\title{
O CONTEXTO UNIVERSITÁRIO ENQUANTO MUNDO DO TRABALHO SEGUNDO DOCENTES NEGROS: DIFERENTES EXPRESSÕES DE RACISMO E COMO ELAS ACONTECEM ${ }^{1}$
}

\author{
Isabela Ariane Bujato ${ }^{2}$ \\ Eloisio Moulin de Souza ${ }^{3}$
}

http://dx.doi.org/10.1590/1413-2311.282.95038

\section{RESUMO}

Levando em consideração a disparidade de negros no espaço acadêmico enquanto mundo do trabalho, este artigo buscou compreender como acontecem os comportamentos racistas e suas diferentes expressões no contexto universitário, considerando a vivência de docentes negros neste espaço. Para tanto, quanto a produção de dados, entrevistas semiestruturadas com cinco docentes de uma universidade pública autodeclarados negros foram realizadas a partir de um roteiro semiestruturado. Por conseguinte, produziu-se quatro categorias através da metodologia de análise de conteúdo. Diante das análises e resultados, observou-se a incidência das três expressões de racismo: institucional, estrutural e individual. É ressaltado o racismo estrutural como sendo uma expressão sempre presente nos discursos, perpassando todas as outras.

Palavras-chave: Racismo. Trabalho. Universidade. Docentes negros.

\section{THE UNIVERSITY CONTEXT AS WORLD OF LABOUR OF BLACK TEACHERS: DIFFERENT EXPRESSIONS OF RACISM AND HOW THEY HAPPEN}

\footnotetext{
${ }^{1}$ Recebido em 7/8/2019, aceito em 16/3/2020.

${ }^{2}$ Universidade Federal do Espírito Santo - Programa de Pós-Graduação em Administração; Vitória - ES (Brasil); https://orcid.org/0000-0002-6736-8390; bujato01isa@ gmail.com

${ }^{3}$ Universidade Federal do Espírito Santo - Programa de Pós-Graduação em Administração; Vitória - ES (Brasil); https://orcid.org/0000-0002-6736-8390; eloisiomoulin@ gmail.com
}

(c) $)$ (1) 9 REAd | Porto Alegre - Vol. 26 - N. ${ }^{\circ} 1$ - Janeiro / Abril 2020 - 210-237. 
Taking into account the disparity of blacks in the academic space as a world of work, this article sought to understand how racist behaviors and their different expressions occur in the university context, considering the experience of black teachers in this space. As for data production, semi-structured interviews with five professors of a self-declared black public university were conducted from a semi-structured script. Therefore, four categories were produced through the content analysis methodology. Given the analysis and results, we observed the incidence of three expressions of racism: institutional, structural and individual. Structural racism is emphasized as an ever-present expression in the speeches, pervading all others.

Keywords: Racism. Labour. University. Black teachers.

\section{EL CONTEXTO UNIVERSITÁRIO COMO EL MUNDO DEL TRABAJO DE PROFESORES NEGROS: DIFERENTES EXPRESIONES DE RACISMO Y COMO ELLAS SE SUCEDEN}

Teniendo en cuenta la disparidad de los negros en el espacio académico como un mundo de trabajo, este artículo buscó comprender cómo los comportamientos racistas y sus diferentes expresiones tienen lugar en el contexto universitario, considerando la experiencia de los profesores negros en este espacio. Por lo tanto, en cuanto a la producción de datos, se realizaron entrevistas semiestructuradas con cinco profesores de una universidad pública negra autodeclarada en base a un guión semiestructurado. Por lo tanto, se produjeron cuatro categorías utilizando la metodología de análisis de contenido. Dados los análisis y resultados, observamos la incidencia de las tres expresiones de racismo: institucional, estructural e individual. El racismo estructural se enfatiza como una expresión siempre presente en los discursos, que impregna a todos los demás.

Palabras clave: Racismo. Trabajo. Universidad. Docentes negros.

\section{INTRODUÇÃO}

Entendendo racialização como um processo discursivo através do qual significados e sentidos raciais são atribuídos, de forma que há um controle e uma classificação de indivíduos a partir de categorias racialmente hierarquizadas (SOUZA, 2018), é necessário compreender a relação das estruturas sociais que reproduzem comportamentos racistas (ALMEIDA, 2018). 
No caso de pesquisas em administração, mais precisamente nos estudos organizacionais, tal olhar também é importante uma vez que a distinção provocada pela racialização de sujeitos produz desigualdades de oportunidade e interfere na subjetividade destes. Há estudos que discorrem sobre esta problemática no que diz respeito às relações raciais, organizações, universidade e mundo do trabalho (TEIXEIRA, 2015; CONCEIÇÃO, 2006; ROSA, 2014; SOUZA, 2017; OLIVEIRA, 2015; MIRANDA; CAPELLE; CUNHA; BUJATO; BARBOSA; SAMPAIO, 2015; LAGE; SOUZA, 2016; NASCIMENTO; OLVEIRA; TEIXEIRA; CARRIERI, 2016).

Concomitantemente, do mesmo modo que é preciso entender a disparidade de docentes negros fora do contexto universitário enquanto mundo do trabalho, é preciso compreender os discursos daqueles que, mesmo sendo minoria (CARVALHO; SILVA, 2014; CARVALHO, 2006), sofrem com ela. A universidade, além da função de transmissão de conhecimento, é formadora de valores dos indivíduos. Mesmo tendo esse papel, ainda "se encarregou de separar os que tinham acesso e os que não pertenciam àquele espaço. Dessa forma, pode inteferir, positivamente ou negativamente, na afirmação de identidades raciais" (RÖESCH, 2014, p. 185) - o que também acontece quando o sujeito negro ocupa a posição de professor (TATE, 2013; RÖESCH, 2014; CARVALHO; SILVA, 2014; CARVALHO, 2006; GOMES, 2004; HOLANDA, 2009; ROËSCH, 2014).

Dessa forma, o presente estudo se faz importante a partir do momento que se propõe ir além de quantidades e representatividades negras nos espaços - que também são ascpetos que precisam ser discutidos cientificamente, buscando entender de que forma o racismo se materializa e como isso afeta, particularmente, os sujeitos daquele espaço no seu dia a dia enquanto mundo do trabalho. Assim, este trabalho se fundamenta com o objetivo de compreender a seguinte sentença: "como acontece o racismo e suas diferentes expressões no contexto universitário, considerando a vivência de docentes negros neste espaço?” . Como sujeitos da pesquisa, considera-se aqui docentes de uma universidade pública, os quais se autodeclaram negros.

Para tanto, são discutidos e apresentados aspectos como a racialização de corpos negros na história das relações sociais brasileiras, atentando para um olhar sobre o preconceito de marca, característico no país. Além disso, diferentes expressões de racismo são também apresentadas, de forma a entender como tais siutações vividas pelos sujeitos dessa pesquisa se solidificam nas relações acadêmicas e de trabalho. O contexto organizacional é também discutido, trazendo a universidade como ponto específico de análise e mostrando 
como a realidade organizacional é construída a partir de um olhar às relações raciais. Em seguida, a metodologia da pesquisa é apresentada e as análises dos dados são organizadas em quatro categorias: (1) "Na academia, ela nunca é considerada intelectual": mulher, docente e negra; (2) e "Nós conseguimos ressignificar a estética negra": características físicas racializadoras"; (3) "É como se eu ficasse um pouco menos preto": racismos e miscigenações e (4) "Como é que ela pode entrar aqui, assim? Da onde que vem?": a universidade como um "não lugar" para o negro. Como considerações finais do artigo, observa-se a incidência das três expressões de racismo: institucional, estrutural e individual. Apresenta-se as reflexões feitas a partir de cada um deles, bem como de que maneira estes aparecem nos relatos. É ressaltado o racismo estrutural como sendo uma expressão sempre presente nos discursos, perpassando todas as outras, uma vez que é a partir dele - levando em consideração o contexto da história das relações raciais que se dá por meio de uma estrutura racializadora que as demais se solidificam.

\section{AS RELAÇÕES RACIAIS NO BRASIL}

O período colonial brasileiro juntamente com o processo de escravidão, no que diz respeito às relações raciais, apresenta-se como momento histórico carregado de distinção. Desde a navegação, europeus que aqui pisaram já não sabiam como denominavam os povos, tamanha estranheza a qual reagiram no primeiro contato (MUNANGA, 2010). Schwarcz (2012) afirma que para eles a natureza era exuberante e paradisíaca, mas os povos, por sua vez, estranhos. Já os cientistas, em meados do século XVIII, denominavam os descobertos como povos de "raças diferentes" devido à cor de suas peles.

Mais tarde, entre os séculos XIX e XX, características morfológicas também são evidenciadas: o tamanho do rosto e do crânio, formato do nariz e lábios; mais uma maneira de estigmatizar os negros, cientificamente, como raça diferente (MUNANGA, 2010). A partir daí, raça passa a segregar, estereotipar e discriminar (SCHWARCZ, 2012); tendo-se, então, o racismo científico no período colonial (TEIXEIRA, 2015). Enquanto escravos, Pereira (2011) apresenta os negros como atores sociais dominados. Porém, mesmo reféns, alguns possuíam uma consciência crítica e de luta, fosse nos quilombos ou nas senzalas. Posteriormente ao processo histórico de "libertação", agora trabalhadores na estrutura social, ocupavam espaços de mão-de-obra desqualificada e massa de manobra da sociedade (PEREIRA, 2011; FERNANDES, 2007). 
Em "Rediscutindo a Mestiçagem no Brasil: Identidade nacional versus identidade negra”, Munanga (1999) apresenta a questão da mestiçagem. No intervalo entre independência e abolição, o autor mostra em seus escritos o quanto a presença do negro foi ressignificada. Mesmo que o plano tivesse sido o desparecimento dos negros com a miscigenação, "no lugar de uma sociedade totalmente branca, ideologicamente projetada, nasceu uma nova sociedade plural” (MUNANGA, 1999, p. 15); uma sociedade de diferentes raças e que, segundo o autor "dão ao Brasil seu colorido atual” (MUNANGA, 1999, p. 15). Além disso, há algo pra o qual Munanga se atenta ao enxergar raça: a mestiçagem tem mais de ideológico do que, propriamente falando, de biológico.

Com o objetivo de unificar a espécie humana, a mestiçagem cria um indivíduo que, diante de suas diferenças raciais "é sempre tratado com ambivalente, visto ora como o "mesmo", ora como o "outro". (MUNANGA, 1999, p. 23). Entre os séculos XIX e XX o Brasil começa a propor caminhos para uma nova nacionalidade. Com muitos ex escravos negros, tal pensamento se torna complicado:

Todo brasileiro é um mestiço, quando não é no sangue, o é nas idéias". Mas, não é por isso - completa - que o Brasil será uma nação de "mulatos", porque na mestiçagem a seleção natural faz prevalecer, após algumas gerações, o tipo racial mais numeroso, que no caso do Brasil é a raça branca, graças à intensificação da imigração européia, ao fim do tráfico negreiro, ao decréscimo da população negra após a abolição e ao extermínio dos índios. Dentro de dois ou três séculos, a fusão entre as três raças será talvez completa e o brasileiro típico, mestiço, bem caracterizado. (MUNANGA, 1999, p. 52)

Munanga (1999) traz os pensamentos de intelectuais como Silvio Romero e Nina Rodrigues a respeito de uma intenção existente quanto a predominância da raça branca na sociedade brasileira. Silvio Romero acreditava que a mestiçagem contribuiria para que as três raças - negra, branca e índia - se transformasse em um povo brasileiro. Porém, apostava na predominância - tanto biológica quanto cultural - branca. Nina, por sua vez, rejeitava uma possível "unidade étnica" (MUNANGA, 1999). O médico apresentou um Brasil ideal: aquele que não misturasse as espécies, já que isso era, por ele, considerado negativo. Para Nina, existia um Brasil que se dividia em dois. De um lado, um país progressista composto por brancos; além de progressista, rico. Do outro lado, um Brasil de negros, pobre e sem perspectiva (SCHWARCZ, 2012; PEREIRA, 2011). "De certo modo, Nina vê na mestiçagem um produto e um resultado diametralmente oposto ao vislumbrado por Romero. Em vez do branqueamento ele vê o enegrecimento" (MUNANGA, 1999, p. 57). Miscigenar era, então, 
uma ameaça ao desenvolvimento do país, pois o negro, visto como inferior, era considerado um atraso para o Brasil (ROSA, 2014).

Houve uma visão tanto positiva quanto negativa no que diz respeito ao processo de miscigenação: Teixeira (2015) afirma que aqueles que entendiam o processo como negativo, eram considerados segregacionistas. Os que positivamente defendiam a miscigenação a fim de extinguir os negros, acreditavam nos benefícios de um possível branqueamento. Darcy Ribeiro e Florestan Fernandes são dois autores que, ao tratarem do marcador raça no contexto do Brasil, apresentam classe e poder. Ribeiro (2006) cria uma pirâmide de estratificação de acordo com posições sociais. Segundo o autor, negros se encontravam no final da pirâmide, como os marginalizados e sustentados pelos dominantes, "classe intrinsicamente oprimida" (RIBEIRO, 2006, p. 192).

Fernandes (2007), por sua vez, enxergava um Brasil binário: brancos opressores e negros oprimidos; brancos beneficiados pela economia, negros reféns dela. Negros como massa de manobra que, após a lei áurea, mesmo libertos, não conseguiram almejar posições de prestigio; permanecendo, assim, como mão de obra barata e desqualificada (FLORESTAN, 2007). Há uma interseção do problema da raça às relações de classe, acreditando que as desigualdades seriam eliminadas no momento em que pensamentos e propostas socialistas fossem surgindo (SILVA, 2000). Com relação à identidade, entende-se que raça e classe são duas coisas distintas; e que neste caso, o contexto histórico tanto escravista quanto póscolonial mostra como aspectos fenotípicos construídos socialmente pelo discurso racializaram as relações (HALL, 2000; 2003). Backes (2006) afirma que mesmo que raça e classe não estejam a todo tempo relacionadas, nem que uma possa sempre se sobressair à outra para explicar as relações de poder, a interseccionalidade entre ambas não pode ser descartada em alguns momentos. Concomitantemente, há o contexto da falácia da democracia racial vivida no país logo após a Segunda Guerra Mundial, que Guimarães (2006) apresenta como sendo uma ideia de que não havia impedimentos de ascensão dos negros na sociedade brasileira, muito menos discriminações raciais. Gilberto Freyre foi um dos precursores deste pensamento, com a intenção de que o Brasil fosse visto como miscigenado, um país de três raças, tolerante e sociável (SCHWARCZ, 2012). Contextualizando o cenário da democracia racial brasileira, consequência de tais pensamentos, Munanga (1999, p. 79) afirma que

Freyre consolida o mito originário da sociedade brasileira configurada num triângulo cujos vértices são as raças negra, branca e índia. Foi assim que 
surgiram as misturas. As três raças trouxeram também suas heranças culturais paralelamente aos cruzamentos raciais, o que deu origem a uma outra mestiçagem no campo cultural. Da ideia dessa dupla mistura, brotou lentamente o mito da democracia racial, "somos uma democracia porque a mistura gerou um povo sem barreira, sem preconceito".

Tem-se então, na história do Brasil, um branqueamento advindo de uma "democracia" (TEIXEIRA, 2015; SILVA, 2000). Democracia esta que ainda persiste em discursos e relações sociais. De acordo com Silva (2000) o que construiu a raça no país foi a própria negação de sua existência, o "embranquecimento" de pesquisadores no debate, a posição social dos indivíduos dos grupos "de cor". Além disso, tanto o mito da democracia racial como a ideia da mestiçagem influenciaram no que diz respeito a classificação de cores no país. Um estudo de Sansone (1996) em Salvador traz um levantamento de cor dos indivíduos e cerca de 36 termos diferentes são encontrados, sendo alguns deles: moreno (o claro e o escuro), pardo, branco, preto, negro, escuro, mulato, sarará, claro, amarelado, formiga, pardo cor de formiga, jambo, marrom, ruivo, japonês, avermelhado, bronzeado, galego, agalegado, e até quase preto. Sansone (1996, p. 174) chama a atenção para o fato de que

[a] cada âmbito ou circunstância da vida privada parecem estar associados alguns termos de cor e uma particular preocupação com a norma somática: na família ("eu sou mais ou menos escuro do que o meu irmão" ou "puxei pela parte branca/negra da família"); na turma (negão); na briga ou no insulto ("coisa de preto"); no carnaval e no universo da música e da religião (a "cultura negra", o baiano e a baiana); e no afetivo (neguinho e neguinha).

Ou seja, pode-se dizer que as estruturas e as relações sociais influenciam na maneira como o fato de "ser negro" será enfrentado pelo indivíduo no que diz respeito à cor da pele e para além dela, uma vez que a classificação carrega consigo aspectos que transcendem apenas uma determinada referência de cor mais clara ou mais escura, de forma a estigmatizar e estereotipar pessoas, discriminando-as a partir do momento em que suas diferenças são atenuadas. As cores se dividem e dividem também a partir daí os espaços na história das relações raciais no contexto brasileiro (SANSONE, 1996). Identidades são formadas e construídas constantemente em contextos específicos, levando em consideração aspectos históricos e culturais.

No que diz respeito à raça, Hall (2000) afirma que este processo precisa ser compreendido. Nesse sentido, há lugares em que ter cor de preto é orgulho, com no gueto ou na "quebrada". Outros, se tornam para eles "não-lugares" pois a cor "mais escura" não lhes dá a oportunidade de pertencimento. São as áreas denominadas respectivamente de "mole" e 
"dura" por Sansone (1996). O contexto universitário, campo do "mundo do trabalho", escolhido para investigação nesta pesquisa pode ser entendido aqui como um "não lugar" que propicia aos [poucos] negros ali presentes enquanto docentes, diferentes sensações; de forma que se posicionar diante da sua cor é se posicionar também diante de relações de poder, de estruturas, de uma religião, um trabalho.

Por fim, Silva (2000) conta que em determinado momento da história discutiu-se entre os pesquisadores a possibilidade da palavra "raça" ser extinta, visto que poderia causar o próprio racismo uma vez que era tida como uma palavra repugnante, repressiva e carregada de opressão. Atualmente, falar sobre raça e racismo se tornou crucial para discutir e combater desigualdades, sejam elas em contextos organizacionais ou não:

\begin{abstract}
Hoje, a luta daqueles que reconhecem as desigualdades existentes no Brasil consiste justamente em defender a importância do estudo da questão racial e do conceito de raça. Enquanto este não for enfrentado por cientistas e pelos próprios negros numa forma de autoidentificação não será possível extirpar as desigualdades tão antigas no cenário nacional, especialmente mediante o seu processo de naturalização (SILVA, 2000, p. 102).
\end{abstract}

Dessa maneira, reforça-se a importância de, através da academia e de demais espaços sociais, problematizar a identidade racial e todas as relações de poder e estruturas que as circundam a fim de desconstruí-la. Acredita-se que a melhor forma de reconhecer a existência de uma problemática ou de uma desigualdade é falando sobre ela. A negação da raça em qualquer contexto, traz consigo a negação do racismo; e a negação deste, por sua vez o perpetua, mesmo que sutilmente e velado. É importante, então, entender como e de quais formas o racismo se manifesta nas relações - discussão abordada no próximo tópico deste trabalho.

\title{
2 RACISMOS E SUAS DIFERENTES EXPRESSÕES
}

No que diz respeito ao racismo em sua forma personificada, Teixeira (2015) o desmembra em três diferentes expressões, as quais se resumem em: estrutural, institucional e interpessoal. O racismo estrutural é, de acordo com a autora, responsável pela desigualdade social entre sujeitos negros e brancos. $\mathrm{O}$ institucional diz respeito às ações racistas perpetuadas por instituições e o interpessoal, por sua vez, trata de um racismo que acontece nas relações estabelecidas entre os sujeitos (TEIXEIRA, 2015). Almeida (2018), por sua vez, também discute um pouco a respeito de cada uma, mostrando como os pensamentos foram avançando de uma forma de racismo para outra. A começar pelo interpessoal ou individualista 
- como denomina o autor -, que é entendido como uma patologia; em algo pautado em aspectos que envolvem o caráter do sujeito. Almeida (2018) acredita que este olhar do racismo traz a ele uma característica muito psicológica e nada política; o que não o faz, na opinião do autor, um racismo de fato. Seu combate fica no campo de indenizações jurídicas. O olhar a um racismo individualista é um olhar que resume os processos aos indivíduos, que particularmente agem de forma isolada, e não a instituições ou a própria sociedade como um todo. Sendo assim, além de imoral o racismo é um crime e os que o colocam em prática nas relações precisam ser punidos. Porém, o autor chama atenção ao fato de que

a concepção individualista, por ser frágil e limitada, tem sido a base de análises sobre o racismo absolutamente carentes de história e de reflexão sobre seus efeitos concretos. É uma concepção que insiste em flutuar sobre uma fraseologia moralista inconsequente - "racismo é errado", "somos todos humanos", "como se pode ser racista em pleno séclo XXI?", "tenho amigos negros", etc - e uma obsessão pela legalidade (ALMEIDA, 2018, P. 28)

Quanto ao racismo institucional, López (2012) discute sobre a ausência de reflexão a despeito do mesmo nas instituições do país, explicada pelo fato de ser difícil identificar e reconhecer mecanismos de racismos institucionais, além das instituições dificilmente assumirem-se como reprodutoras e produtoras de tais comportamentos (LÓPEZ, 2012). De acordo com Silva (2017), esta forma de racismo pode ser manifestada tanto em ações no dia a dia do trabalho, como também através das próprias normas da instituição. "Em qualquer caso, o racismo institucional sempre coloca pessoas de grupos raciais ou étnicos discriminados em situação de desvantagem no acesso a benefícios gerados pelo Estado e por demais instituições e organizações" (SILVA, 2017, p. 129).

Complementando as discussões, Almeida (2018) apresenta o racismo institucional como um olhar avançado nos estudos das relações raciais, pois permite a visão de um racismo que ultrapassa o campo do caráter dos indivíduos e caminha para questões que envolvem o funcionamento das instituições e organizações. Nesse sentido, o funcionamento de uma organização ou instituição diz respeito a como vantagens e desvantagens raciais serão vivenciadas. Nesse sentido, entende-se que o racismo é uma característica da sociedade; deixa-se de lado a ideia de ações isoladas e passa-se a entender a hegemonização das instituições por parte de determinados grupos. Há um poder exercido por tais grupos dominantes; consequentemente, seus interesses são institucionalizados e as regras, por sua vez, impostas. Almeida (2018) deixa claro que tal domínio se fortalece a partir da raça, através da qual. brancos predominam os espaços. E afirma: 
é no interior das instituições que os indivíduos tornam-se sujeitos. visto que suas ações e seus comportamentos são inseridos em um conjunto de significados previamente estabelecidos pela estrutura social. Assim, as instituições moldam o comportamento humano, tanto do ponto de vista das decisões e do cálculo racional, como dos sentimentos e preferências (ALMEIDA, 2018, P. 30).

Nesse sentido, quanto menor for a discussões nos espaços institucionais hegemônicos, maior será a desigualdade e o domínio racial. Diferente do xingar ou insultar, o racismo institucional é velado uma vez que se dificulta a presença do negro em determinados espaços institucionais. Para isso, não necessariamente é preciso normas ou regimentos, mas há obstáculos formais presentes nas próprias relações sociais (WERNECK, 2016; SILVA, 2017). Por conta de toda hegemonia racial institucional, o racismo pode vir a ser menos evidente, mais sutil e menos identificável; por consequência, a condenação pode não acontecer como em racismos considerados individuais, uma vez que já existem forças e relações de poder bem estabelecidas (ALMEIDA, 2018).

No que diz respeito ao estrutural, pode-se dizer que de alguma forma este sempre existiu, visto que os negros durante toda história ocuparam os últimos lugares e posições, sejam elas econômicas ou políticas (OLIVEIRA; OLIVEIRA, 2015). Almeida (2018) enxerga a concepção estrutural como a própria explicação de instituições condicionadas a determinadas ações, como algo previamente colocado. Nesse sentido, o próprio racismo da instituição é parte da uma estrutura, sendo as instituições apenas materializações desta, reproduzindo-a. "Dito de modo mais direto: as instituições são racistas porque a sociedade é racista" (ALMEIDA, 2018, p. 36). São formadas por aspectos estruturais tanto sociais, quanto políticos e econômicos; aspectos estes que influenciam nas ações das pessoas que a constituem. Assim, o autor rebate todos os pensamentos anteriores (ALMEIDA, 2018, p. 38) ao dizer que:

\footnotetext{
o racismo é uma decorrência da própria estrutural social, ou seja, do modo "normal" com que se constituem as relações políticas, econômicas, jurídicas e até familiares, não sendo uma patologia social e nem um desarranjo institucional. O racismo é estrutural. Comportamentos individuais e processos institucionais são derivados de uma sociedade cujo racismo é regra e não exceção. O racismo é parte de um processo social que ocorre pelas costas dos indivíduos e thes parece legado pela tradição.
}

Por outro lado, salienta que este olhar de um racismo estrutural não pode isentar os sujeitos com relação à responsabilidade de um discurso racializador que é vivenciado na prática por eles. Medidas devem ser tomadas, mas não apenas jurídicas (ALMEIDA, 2018), entendendo que o racismo não é um ato isolado e que é preciso pensar de forma macro para 
que não se reproduza a desigualdade racial nas relações. Clealand (2013), por sua vez, afirma que muitas vezes o que a sociedade enxerga é, de fato, apenas o racismo individual - em sua maioria, atos explícitos -, apesar de existir diversos casos de negros que não são empregados, ou não conseguem promoção no ambiente de trabalho e oportunidades de estudo por conta da raça, de forma que "a experiência da discriminação se tornou algo comum na vida dos negros criando uma realidade social desigual da dos brancos" [tradução nossa] (Clealand, 2013, p. 1623). Ao categorizar tipos de raça, as pessoas categorizam indivíduos e suas cores: qual a cor vista como ameaçadora, perigosa e criminosa e a cor que hierarquiza de acordo com classes sociais (NADAL et al, 2012).

Nogueira (2006) apresenta um estudo que traz à tona a existência de duas noções de preconceitos, denominadas por ele como preconceito de marca e a outr, por sua vez, como preconceito de origem. A despeito disso, mostra aos leitores uma comparação, de como Estados Unidos e Brasil externam de formas distintas os atos preconceituosos. Segundo o autor, há o preconceito de marca, o qual diz respeito ao preconceito racial que envolve a aparência física do outro, seus traços, sua forma de falar. Este é predominante no Brasil, enquanto nos Estados Unidos o preconceito está baseado na origem da pessoa: está ligado ao grupo étnico, diz respeito à questão de sangue, de forma que uma pessoa pode não ter fenótipos negros, mas ser considerada e discriminada como tal.

Ao tratar de discurso, Van Dijk (2012) traz sua visão a respeito das elites simbólicas que, segundo ele, podem ser compreendidas como entidades, instituições, pessoas e representações sociais que detém o poder da palavra e do discurso perante a sociedade: igreja, governantes, grandes empresários e investidores, a mídia - e sua influência na propagação de comportamentos racistas. Trata sobre um racismo moderno (IANNI, 2004), carregado de expressões e falas, contribuindo para uma análise semântica da temática. De acordo com Van Dijk (2012) discursos racistas são frutos de uma manutenção da face em aparência positiva de si mesmo. Nesse sentido, as pessoas tomam cuidado ao expressar seus racismos para que assim possam não se auto afetarem e para que mantenham uma boa impressão. É o típico "não tenho nada contra negros, mas é que...”.

Ante a isso, o autor discorre a respeito de algumas formas de identificação deste racismo moderno e velado, porém sempre negado: a transferência, quando o preconceito é negado ao transferir a culpa para terceiros, como "eu gosto de negros, mas o meu vizinho..."; a mitigação, que acontece a fim de minimizar afirmações através de eufemismo, tornando o discurso mais leve; a provocação e culpa da vítima, meio através do qual os discursos são 
sempre justificados nos próprios negros, de forma que as condições dos mesmo são frutos de falta de esforços por parte destes, por exemplo; a reversão, mais conhecida como o famoso racismo reverso, em que as pessoas acreditam que, na verdade, negros é que discriminam brancos; e, por fim, a justificativa, que é aquela que, de uma forma ou de outra, passeia por todos os pontos, pois é vista socialmente como uma forma do eu, sempre positivo, se resguardar (VAN DIJK, 2012).

\section{MUNDO DO TRABALHO, CONTEXTO UNIVERSITÁRIO E COMPORTAMENTOS RACISTAS}

As desigualdades estruturais e institucionais no mundo do trabalho se relacionam a corpos físicos (COTTINGHAM; JOHNSON; ERICKSON, 2018). Desde quando a abolição se concretizou e os negros ocuparam posições subalternas enquanto trabalhadores por terem sido considerados mão de obra desqualificada, instaurou-se racismo e, a partir do momento em que políticas públicas não foram pensadas para que tal realidade chegasse ao fim, este se solidificou e permaneceu (BENTO, 2002).

Um estudo do Instituto de Pesquisa Econômica Aplicada (IPEA), "Retrato das Desigualdades de Gênero e Raça - 1995 a 2015" mostra que no que diz respeito ao mercado de trabalho, há uma discrepância que coloca homens brancos no topo da pirâmide e mulheres negras em sua base (IPEA, 2017). Ao discutir mulheres negras no mundo do trabalho, Conceição (2016) apresenta em seu texto dados da Pesquisa por Amostra de Domicílio (PNAD) do ano de 2012 a respeito da composição da sociedade brasileira: homens e mulheres, brancos e negros. Mulheres negras se apresentam como $26,54 \%$ da população, enquanto brancas, $24,36 \%$. No caso dos homens, Conceição (2016) traz dados de $26,43 \%$ de negros, enquanto $21,86 \%$ brancos. Ante a isso, a autora afirma que o favorecimento de certos grupos sociais na hora de empregar indivíduos é uma forma de propagar a desigualdade do país. Ações de organizações públicas e privadas têm favorecido mulheres brancas em detrimento das negras quanto às oportunidades; quando há o fortalecimento negro, este é mais focado nos homens que nas mulheres (CONCEIÇÃO, 2016).

No contexto da universidade enquanto mundo do trabalho, no que diz respeito às relações raciais, tal constatação não é diferente. Na prática, como afirma Silva (2008) e levando em consideração estes aspectos, a democracia no ensino superior está longe de acontecer quando apenas $1 \%$ dos docentes das universidades públicas do país é negro. 
Carvalho (2006) ironiza que não seria trabalhoso organizar qualquer contagem, uma vez que os docentes negros são poucos e os que se identificam como tal, sabem quem são seus companheiros de trabalho, ou seja, possuem consciência de que são minoria (CARVALHO, 2006). Em sua pesquisa, Gomes (2004) analisa experiências de discriminação sofridas por docentes negros na Universidade de Brasília (UnB), observando a existência de um estigma negativo, de forma que os docentes se sentiam atuando em lugares que não pertencem, de fato, a eles; lugares nos quais a sociedade não os aceita. Mesmo diante do sentimento de não pertencimento, os docentes negros entrevistados, de acordo com a autora, aproveitaram da situação para resgatar suas identidades, dispostos a enfrentar as barreiras no mundo do trabalho (GOMES, 2004).

Tate (2013), por sua vez, desenvolve um trabalho que discute a tolerância de docentes brancos com relação a negros. Tolerância no sentido de ignorar qualquer prática racista na organização ao considerar a raça como comum e entender que "sim! Está tudo bem!"; como se aceitar negros no espaço da academia fosse, de antemão, um grande instrumento de combate ao racismo. Porém, o que Tate (2013) mostra é que, no que tange à universidade, este é um espaço de trabalho em que negros são considerados “corpos fora do lugar". Por serem poucos, os docentes em sua maioria são vistos pelos outros como aqueles que representam a sua raça. Essa representação traz um peso maior e faz com que professores negros sejam sempre "observados"; seja quanto à maneira correta de ensinar ou até quanto à qualificação suficiente para estar em uma sala de aula. De acordo com a autora, a tolerância representa civilidade e precisa ser notada nas relações de trabalho da universidade para que tudo permaneça "nos eixos" (TATE, 2013). Na academia como mundo do trabalho, raça passa a ser marca que representa na maioria das vezes a falta de alguma coisa: de inteligência, de capacidade, de proficiência. E por outro lado, o excesso de outras: de desconfiança, de anomalia, de diferença. "A luta diária de acadêmicos negros em instituições de ensino superior é a de resistir à sua localização no espaço de abjeção por causa da pele" (TATE, 2013, p. 2479 - tradução nossa). A partir das reflexões expostas pela autora, é possível trazer alguns aspectos para a realidade brasileira, mais especificamente para a universidade aqui escolhida como campo de análise de tais comportamentos racistas.

\section{METODOLOGIA}


Quanto aos caminhos percorridos na construção deste artigo, a abordagem metodológica de caráter qualitativo se apresenta como norteadora de toda análise e discussão. Justifica-se a escolha de tal abordagem pelo fato de procurar compreender o fenômeno das relações raciais envolvendo diferentes expressões de comportamentos Para tanto, a pesquisa qualitativa permite uma análise e interpretação filosófica dos dados, baseando-se em diferentes estratégias de investigação, que podem ir além de textos e imagens, assumindo uniformidades (CRESWELL, 2003) e trazendo a reflexão de que o mundo social está diretamente ligado à realidade do ser humano; não se pode negar uma objetividade, mas é preciso entendê-la como parte dos sujeitos e das estruturas, de como o mundo é visto e vivido pelas pessoas (COLBARI, 2014).

Retoma-se, então, a problemática levantada como objetivo deste artigo: "como acontece o racismo e suas diferentes expressões no contexto universitário, considerando a vivência de docentes negros neste espaço?". Para tanto, se tratando da categoria raça, considera-se como sujeitos desta pesquisa professores de uma universidade federal, autodeclarados negros. Como método de produção de dados desta pesquisa, a entrevista semiestruturada é realizada a fim de tentar analisar a compreensão de mundo e o ponto de vista dos entrevistados (GASKELL, 2005) com base em seus contextos e vivências sociais, mais especificamente o mundo do trabalho e as relações raciais. Nesse sentido, 05 (cinco) docentes foram entrevistados. Dos cinco, dois se identificaram como gênero feminino e três como gênero masculino. Com relação ao espaço de atuação na instituição, as duas professoras compõem o Centro de Educação, enquanto dois fazem parte do Centro de Educação Física e Desportos e, o outro, do Centro de Ciências da Saúde.

O projeto de pesquisa foi submetido e aprovado pelo Comitê de Ética e Pesquisa (CAAE 0377418.2.0000.5542). Em conformidade com procedimentos éticos descritos na Resolução $n^{\circ} 510$ de 2016, que estabelece princípios éticos nas pesquisas da área de ciências sociais no que diz respeito a pesquisas que envolvem a participação de sujeitos diretamente na produção dos dados (BRASIL, 2016), a instituição não será identificada, bem como os docentes. Para tanto, nomes fictícios foram dados a cada um dos 05 (cinco) entrevistados.Após a transcrição de entrevistas, os dados produzidos foram analisados por meio da análise de conteúdo (AC). De acordo com Colbari (2014), a AC se baseia em formas um tanto quanto descritivas e em categorizações que são, por sua vez, construídas de forma lógica-dedutiva, bem como através de uma dimensão interpretativa e de quadros conceituais. Neste trabalho a AC foi operacionalizada qualitativamente e à mão, sem a ajuda de softwares. 
As categorias de análise - bases para os resultados e discussões - ajudam a entender o discurso, pois as técnicas permitem ir além da fala, abrangendo aspectos sentimentais, de interesse, bem como possíveis simbologias (COLBARI, 2014; BARDIN, 2004).

Foram elaboradas quatro a priori de acordo com as sentenças que compõem o objetivo proposto neste trabalho: diferentes expressões de racismo no contexto universitário de docentes negros. As categorias se dividem em: (1) "Na academia, ela nunca é considerada intelectual": mulher, docente e negra; (2) "Nós conseguimos ressignificar a estética negra": características físicas racializadoras; (3) "É como se eu ficasse um pouco menos preto": racismo e miscigenações e (4) “Como é que ela pode entrar aqui, assim? Da onde que vem?”: a universidade como um "não lugar” para o negro. Através do método análise de conteúdo no tratamento dos dados foi possível trazer sentido aos relatos dos entrevistados, suscitando a compreensão de entendimento de mundo (COLBARI, 2014) destes no que diz respeito às vivências racistas em seu mundo de trabalho enquanto contexto universitário. O tópico que se segue, de resultados e discussões, apresenta as análises a partir de cada categoria criada.

\section{RESULTADOS E DISCUSSÕES}

\section{1 "NA ACADEMIA, ELA NUNCA É CONSIDERADA INTELECTUAL": MULHER, DOCENTE E NEGRA}

No relato de Stela, quando perguntada a respeito de como suas características físicas influenciam nas relações de trabalho na academia, traz uma visão criada pelos sujeitos deste espaço sem reflexão e consciência da trajetória de negros e negras no Brasil, onde "tudo é racismo" e reações diante dos comportamentos racistas sofridos pela entrevistada são vistas sempre como exagero e acabam por intitulá-la:

Do ponto de vista racial? Não tem algo assim, tão evidente. O que dizem muito e que eu tenho plena consciência de que é a marca do racismo... que dizem que eu sou uma pessoa que falo muito. Então eu falo pouco, né... mas quando eu falo, a minha fala parece que agride. Então é como seu eu fosse, assim... aquela negra revoltada. Parece que é essa imagem que eu vendo pras pessoas. Que fica calada, mas na hora que tá calada tá demonstrando pela expressão tudo que pensa. Isso pode ser, sim, um acumulo, né, de tudo que eu já passei. Então eu não consigo disfarçar. Mas, assim... nada. Nem uma parte do seu corpo ou algum traço? Eu tô achando...tá mudando...não é que tá mudando. As pessoas estão mais polidas pra chegar. Mas a coisa da mulata? Essa foi uma marca a minha vida toda: mulata. Mulata e morena, que é pior ainda que mulata pra mim. Morena. Então essa "morena linda" morena não sei o que...esse tipo de representação. Mas aqui, é.. como eu te falei, é... a 
etiqueta é outra. A etiqueta que vai pra mim é do "exótico" [...].E aí também nessa coisa da minha postura, dizem também que é... como se não pudessem falar nada perto de mim. Tipo "ai, não pode falar nada que agora pra Stela tudo é racismo”. Então, aquelas caras e bocas. E é isso, assim... aquele negro revoltado, como diria Adbias do Nascimento. Tô sempre revoltada. (Stela, Centro de Educação).

A "negra revoltada", por exemplo, é uma marca criada para a docente em razão da sua reação ou do ato de se posicionar diante do racismo. Stela afirma que diante do racismo, muitas vezes não consegue controlar as suas reações, por conta de tudo que já vivenciou como mulher negra durante as fases de sua vida. Ao mesmo tempo, mostra como isso chega ao outro: "agride". Neste caso, é possível refletir na possibilidade de quem fala em usar de um discurso no qual se mostra agredido ou incomodado como forma de tomar cuidado com a expressão do seu próprio racismo, se resguardando de julgamentos e mantendo uma boa impressão (VAN DIJK, 2012); o que explica o fato de que "as pessoas estão mais polidas pra chegar". Além disso, transfere-se uma culpa (VAN DIJK, 2012) à docente por conta da sua reação: "como se não pudessem falar nada perto de mim" porque "agora pra Stela tudo é racismo".

A mestiçagem também atravessa a trajetória de Stela quando a docente afirma que durante toda sua vida foi "lida" como mulata ou morena, mas nunca como negra, maneira pela qual se identifica. O termo "mulato", como já discutido aqui, é contado na história das relações raciais como uma nova forma de se pensar um Brasil mestiço entre os séculos XIX e $\mathrm{XX}$, tempos nos quais imperava a ideia de diminuir os negros e fazer prevalecer as pessoas brancas no país (MUNANGA, 1999). Além disso, assim como Sansone (1996) apresenta, existem distintos levantamentos de cor no Brasil. No mundo do trabalho de Stela, esses levantamentos a colocam em determinadas posições como sujeito a ponto, neste caso, de levar a uma sexualização da mulher negra a partir do momento que o termo "mulata" acompanha o "exótico".

Outra entrevistada do mesmo departamento compartilha a influência da sua identidade racial no seu mundo do trabalho:

Claro, sempre, né. Porque uma mulher negra na academia ela nunca é considerada intelectual, uma pesquisadora, inteligente, né. Então. Então voche acha que os estereótipos... Sim. Eles reforçam isso, né. Estereótipo de uma mulher negra último tom, cabelo crespo. Adora dançar, né. Meu grupo de pesquisa a gente tem práticas teóricas... teoria e prática teórica. Prática da realidade vai pras teorias... aí a gente vai pras formas do corpo, joga pra corporeidade, volta pra cá... reflete. É esse processo. Então, quer dizer, é se divertir, né... dança, corpo... como assim na academia, né? Então são... vão 
reforçando as caixinhas, né, que nos colocam da incompetência na verdade, né. Então pra mim é isso. (Cida, Centro de Educação).

Pelo relato de Cida percebe-se que a mulher negra e o contexto universitário não são vistas como coisas correlatas. Cida carrega várias características marcantes consigo, como o cabelo, a pele e posições de atuação dentro do seu espaço de trabalho mas que, porém, continuam colocando a universidade como sendo um não lugar para ela. Nesse sentido, a posição de "professora" não lhe é atribuída: a negra é tudo, menos acadêmica e intelectual. Essa visão é apresentada por Tate (2013), no sentido de que em um espaço como o universitário, a raça é sempre estigmatizada: ou falta algo no docente negro, ou ele tem demais. No caso da entrevistada, na visão do outro lhe falta a competência, a inteligência e a capacidade; enquanto isso, suas características fenotípicas, além de a estereotiparem, são vistas em excesso - como a "mulher negra último tom". Novamente o que Sansone (1996) discute a respeito da cor e divisão de pessoas e dos espaços. Assim, Cida é julgada negativamente (GOMES, 2004), o que a coloca a afasta da posição de professora; e as palavras "negra" e "acadêmica" são, a todo o momento, afastadas uma da outra e nem um pouco evidenciada juntas.

Observando todo o processo histórico aqui discutido envolvendo brancos e negros no Brasil e entendendo como isso ainda permanece nas relações, pode-se refletir a respeito do que Almeida (2018) e Teixeira (2015) apresentam como sendo um racismo estrutural. O termo "mulata", por exemplo; a mulher vista somente de forma negativa até os dias de hoje e a falta da capacidade do negro resumida às suas características que, da mesma forma, desde os tempo coloniais são vistas com estranheza pelos europeus (MUNANGA, 2010), retratam lugares e posições que atravessam contextos e são a consequência das relações de poder racistas e hegemônicas - ou seja, fazem parte de uma estrutura social, política, cultural e econômica (ALMEIDA, 2018).

O próximo ponto a ser discutido traz à tona um sujeito negro que, estando em uma universidade que é campo de trabalho em sua maioria branco, se depara com posições que exigem dele determinadas reações diante das diferentes expressões de racismo.

\section{2 "NÓS CONSEGUIMOS RESSIGNIFICAR A ESTÉTICA NEGRA": CARACTERÍSTICAS FÍSICAS RACIALIZADORAS}


As características físicas como o cabelo, por exemplo, seja ele black ou não, dread ou não, marca o negro socialmente no seu mundo do trabalho, ao mesmo tempo que diz respeito a uma postura com relação à sociedade - o que novamente reforça o racismo estrutural (ALMEIDA, 2018; TEIXEIRA, 2015). Como o entrevistado Jordino conta, o dread antigamente produzia uma posição de bandido ao negro. Atualmente, diante de outros contextos e momentos históricos, sociais e culturais, o negro de dread é intelectual:

"eu tenho um formato de nariz e lábios que não são aqueles traços que nós entendemos nos nossos traços sociais como traços negros, mas o cabelo pixaim e a pele escura são os dois sinais mais fortes que estabelecem as relações étnicas raciais no Brasil. Então o meu cabelo ele é um elemento utilizado pelos interlocutores, vez ou outra forma, de forma negativa. Agora até isso tem sido muito curioso, por exemplo, quando comecei a usar dread em 2004 pra 2005, acho que tinha só eu e mais uma pessoa, era um comum sério, essas portas magnéticas de banco era uma loucura entrar, sempre tratava e eu já fui confundido com sequestradores, até. [...]. Se nos anos 90, $o$ dread era um estereótipo associado ao uso de drogas, ao roubo, hoje o dread segundo eles é um símbolo de um negro intelectual, já ouvi de policiais que basicamente um negro com dread eles já sabem que é um negro da (nome da universidade), eles nem mexem. Os contextos mudam também, né? Mas não deixa de ser uma leitura racializada né? Enfim, o cabelo é uma marca muito presente nas relações raciais, novamente num contexto histórico, isso é muito engraçado, porque quando comecei a usar dread em 2004 até 2006 eu escutava tanta fala no sentido de desqualificar meu cabelo, discriminar, tipo: "corta Jordino, seu rosto é tão bonito, deixa o cabelo curtinho." E aí nesse processo de reeducação da sociedade Brasileira, aí que eu falo da importância do negro que ele reeduca a sociedade, nós conseguimos ressignificar a estética negra, então quando hoje nós observamos um conjunto de jovens com o pixaim pro alto, o dread hoje ele é visto em bons olhos, não vou dizer sempre, mas diferente do que era antes, eu percebo que ouve um tempo que o meu cabelo ele produzia muita dificuldade, hoje não tanta, mas o saber lidar, isso não é regra" (Jordino, Centro de Educação).

O black, trazido pelo entrevistado Sérgio, por sua vez, representa para ele resistência; ao mesmo tempo que em outros espaços, como no caso o que ele ocupa no Centro de Ciências da Saúde, não é visto como algo "clean":

mas eu vejo algumas falas, por exemplo, se eu tivesse o cabelo rastafári, black... eu não sei se eles me aceitariam tanto quanto, entendeu? Eu acho que ia ouvir mais piadinhas no sentido de como eu já ouvi, não pra mim, isso que to querendo dizer. Porque sempre pra mim vem a fala de... de... é como se eu fosse o "negro suave". Você acha que sua posição que te coloca nessa situação? Como assim negro suave, por exemplo? É como se... eu não tenho um black, não tenho... entendeu? Eu não uso... não tenho tranças, essas coisas que são mais... que ainda existem pessoas que acham que isso não é "clean", sabe? Não é... pra um enfermeiro, que trabalha de branco e visa a limpeza, entendeu... isso ainda tá muito atrelado á sujeira. Eu já ouvi isso de alguns professores: "ah, se você quiser usar um black você usa...", mas não fala assim do negro, entendeu? Fala de forma geral: "vai pras artes". Mas na enfermagem o negro sempre tá com o cabelo cortado, assim, ou mais. Talvez por isso não sofra tanto quanto se eu tivesse mais essa coisa da negritude, em 
termos dos meus traços, de cabelos afro, né... black, por exemplo (Sérgio, Centro de Ciências da Saúde)

A partir do momento que um negro sem black é mais clean, ele continua sendo um modelo de "negro clean", assim como o negro com dread entra em uma identidade de "negro intelectual". Mesmo que os contextos históricos e culturais se modifiquem com o passar do tempo (BACKES, 2006), os indivíduos continuam atribuindo marcas sociais ao outros de acordo com suas características, como se via desde períodos coloniais (IANNI, 2004; SCHWARCZ, 2012).

O que se observa é que, a todo momento, traços e características físicas, sejam elas vistas como marcas sociais ou não, racializam (IANNI, 2004; SCHWARCZ, 2012). Assim, as características racializadas sempre coloca o negro em uma posição. Posição que leva a uma postura (e vice-versa) e postura essa, por sua vez, que leva à reflexão:

[...] o fato de eu ser, antes de ser docente, ser uma pessoa minimamente conhecida, eu acho que muitos alunos já me conhecem antes, até pela disciplina que eu ofereço, mas voltando na sua pergunta, eu quero tentar lembrar algum episódio, existem comentários que se revestem de elogio que se ele não é racista, mas eles são produzidos a partir de uma ideia racializada, o que quero dizer com isso? Nós negros somos vistos pela sociedade a partir de um lugar social que se chama de lugar de raça, esse lugar é um lugar de visibilidade do outro numa relação assimétrica de poder marcada pela ideia de raça e pelo racismo, nós negros quase sempre respondemos em nome de uma coletividade, então muitas vezes, quanto estou falando eu percebo que as pessoas escutam como se fosse uma voz coletiva, os brancos não, eles tem respeitado a sua singularidade humana, quando Maria fala é Maria que está falando, não são todos os brancos, quando João fala é João que está falando, ninguém pensa numa coletividade, mesmo que ele faça uma fala em torno de um coletivo, a pessoa que está falando faz isso, o êxito é dele, o erro é dele. (Jordino, Centro de Educação).

Mesmo que o momento histórico, social e cultural seja diferente e de que, de alguma forma, como afirma Hall (2000), o negro de hoje traz consigo aspectos que podem diferir daqueles que envolviam o negro das senzalas - consequência, novamente, dos contextos. A racialização prevalece e, como afirma Ianni (2004) bem como Schwarcz (2012), classifica, posiciona e gera conflitos de desigualdade e hierarquia diante da diversidade.

Neste caso, levando em consideração o contexto universitário enquanto mundo do trabalho, ao afirmar que o colega docente que se identifica como negro é "revoltado", por exemplo, ou é mais negro ou menos negro por se portar ou carregar consigo características diversas - ao mesmo tempo em que não -, as relações se pautam no ato de, a todo o momento, se afirmar coisas sobre o outro; seja aquilo que ele deveria ser, ou não (TATE, 2013). 
Trazendo para o campo de estudo desta pesquisa, a partir do momento em que os docentes não são vistos como comuns diante de seus demais colegas de trabalho e pessoas do ambiente "universidade" e, por sua vez, as opiniões ou atitudes destas os limitam e os desprezam, o racismo acontece. Num primeiro momento pode ser enxergado como institucional, se tratando do ambiente universidade como tal, que carrega consigo normas e relações de poder hegemônicas. Através de um olhar mais macro, as falas e comportamentos trazem o racismo como decorrência de uma estrutura social (ALMEIDA, 2018; VAN DIJK, 2012; TEIXEIRA 2015).

\section{3 "É COMO SE EU FICASSE UM POUCO MENOS PRETO": RACISMO E MISCIGENAÇÕES}

Ao mesmo tempo, quando se volta para a posição "professor", se criam outras impressõess, como relata Eduardo:

E aí tem uma questão pra sua pesquisa, não sei se pode ser ponto de análise. Que é o seguinte: eu percebi que a partir do momento que eu me tornei professor, é como se tivesse passado... tirado uma camada da minha negritude, entendeu? Ao mesmo tempo que quando eu fui da graduação e daqui do bairro eu me senti preto, quando eu passo a ser professor, é como se uma camada... é como se eu ficasse um pouco menos preto (Eduardo, Centro de Educação Física e Desportos).

Quando o negro ocupa determinados espaços, pode haver também o "embranquecimento" do mesmo, embranquecimento este que está presente nas relações raciais brasileiras desde o projeto de miscigenação e da democracia racial, através dos quais a raça no Brasil foi constantemente negada nos espaços (SILVA, 2000) e os quais Munanga (1999) traz como processos históricos ideológicos e políticos, e não biológico. Deste modo, a função da docência pode trazer ao negro uma posição diferente em determinados lugares, mudando assim as impressões com relação a ele mesmo:

Então em outros momentos, quanto à questão da estética: "ah, você é um preto bonito", né? Ou "você tá arrumado", ou "você tem características brancas". Então isso meio que... isso já... eu não aceito. Não é que não aceito. Eu acho meio desnecessário, na verdade, esses comentários até mesmo entre os professores da universidade. Que tem necessidade de falar que você é bonito, que eles acham bonito, mas porque eu tenho características brancas, entendeu? Até na minha boca, ou até mesmo na minha forma de comportamento. Porque eu confesso, assim... eu não uso dread, essas coisas. Uma coisa que te caracterize mais? Mas porque eu não fui criado nesse ambiente. Eu não fui criado. Eu não preciso colocar pra dizer que eu sou negro. Eu acho que eu sou negro porque eu sou. E pronto. Mas eu acho que o desafio maior de ser negro na universidade é você realmente ocupar os espaços. Porque o tempo todo que você se cobra que você tem que ocupar 
espaço. Porque não é só você, nunca é só você. Você tá sendo espelho pra outros (Sérgio, Centro de Ciências da Saúde).

Ele não é bonito, mas é um "negro bonito", ou um "negro revoltado", "negro inteligente" e não apenas "inteligente". A qualidade é acessória e advinda dessa posição identitária (HALL, 2003), que a todo momento é realçada. Esta reflexão nos leva novamente e evidentemente a um racismo estrutural (TEIXEIRA, 2015; ALMEIDA, 2018). Diferentemente de como acontece com outros sujeitos que não se identificam como negros: não se ouve dizer "branco bonita", "branca revoltada", "branco inteligente". que se explica pelo processo racialização na história do Brasil (IANNI, 2004; MUNANGA, 1999), através do qual posições foram estabelecidas entre brancos e negros e, por consequência, um processo de desigualdade (MUNANGA, 2010; TEIXEIRA, 2015) que se atenua pelos dias de hoje e corrobora para que comportamentos racistas em espaços como a universidade ainda sejam presentes.

\section{4 “COMO É QUE ELA PODE ENTRAR AQUI, ASSIM? DA ONDE QUE VEM?”: A UNIVERSIDADE COMO UM 'NÃO LUGAR” PARA O NEGRO}

Nos relatos de Stela e Cida que formam esta categoria, ambas contam experiências em seus mundos de trabalho - que coincidentemente se dão no mesmo departamento - e se é observado como o racismo estabelece espaços e pertenças às mesmas de acordo com suas identidades raciais; por consequência, observa-se também como Stela e Cida se posicionam diante do que lhes é estabelecido socialmente. Stela conta de uma vivência em um momento recente de sua chegada à universidade, de uma situação que aconteceu em determinado setor em que atua como professora:

Eu tinha 15 dias aqui na (nome da universidade). Quando eu cheguei pra tomar posse aqui, tava tendo uma ocupação e depois, logo em seguida, entrou em greve. Outubro de 2016 e depois já foi uma greve. Então não tive experiência de conviver com turmas e tal. E aí fazia 15 dias que eu tava aqui, a gente ainda tava montando essa sala. É....uma sala nova, de professores. Ela tinha só algumas mesas e armários, mas não tinha cara, ainda, de sala, né. Então a gente tava conseguindo lixeira, a gente tava conseguindo papel, lápis, caneta... essas coisas. E tem um setor aqui, não posso dizer, né, por conta de todo um sistema ético, mas... tem um setor aqui no qual a outra professora, que é negra também... e se você entrevistá-la, ela vai te contar outras histórias, né... e talvez mais graves ainda. Mas ela tinha ido lá nesse setor e pegado, assim... lixeira, grampeador... materiais de escritório. E como eu tinha ido, um dia antes, com a minha chefe de departamento nesse mesmo local e a minha chefe, ela... tem uma porta de vidro, tem o guichê... e tem uma porta de vidro. A minha chefe, ela passou pelo guichê, entrou por essa porta de vidro e foi direto falar com o chefe, pra pedir alguma coisa com ele 
lá, que eu não lembro o que era. Então quando eu fui no outro dia, sozinha, eu... essa professora daqui, né, da minha sala, falou "olha, fui lá agora e peguei”. Só que esse funcionário não estava na hora, quando ela foi. Por isso que ela não passou por isso. Aí eu cheguei no guichê, falei bom dia. Ele tava com duas funcionárias no computador. Elas de pé, olhando pra tela. Ele olhou pra mim e continuou no computador. Não falou nada. Aí eu pensei assim: "ah, então tá bom...então vou passar reto", né? E fui. E fui direto falar com o chefe dele. Aí ele chega gritando na sala, gritando com o chefe dele e dizendo: "como é que é isso? Como é que ela pode entrar aqui, assim? Da onde que vem? Não respeita nada! Tem uma placa bloqueando a passagem!"’. E foi falando, foi falando... e daí no fim da conversa, de tudo que ele falou que tinha regras, que eles tavam tentando organizar as coisas e que quando uma pessoa faz isso ela acaba estragando toda uma organização. Aí ele gritou pra esse chefe e disse "não deixa mais essa menina entrar aqui não, viu?!". Aí eu peguei e saí da sala, voltei pro guichê, fiquei na parte de fora e daí ele veio, pegou as coisas. Daí eu tinha que assinar, lápis, caneta, borracha...tudo. Aí peguei, só enfiei a mão assim, por debaixo do guichê, assim, do vidro, e falei: "olha, só uma coisa pra te falar... eu não sou menina, tá? Eu tenho nome e talvez você não se lembra: ontem minha chefe me apresentou pra você. Meu nome é Stela". Eu não falei "professora". Falei "meu nome é Stela e eu tô aqui recente na (nome da universidade). Então, posso até ter cara de menina na sua opinião, mas eu não sou, tá?". Aí ele: “não, desculpa, professora. É porque tem regras"... enfim. Ficou uma situação muito ruim, né...óbvio. (Stela, Centro de Educação).

Inicialmente, analisando a situação e baseando-se nas ideias de Almeida (2018) e Teixeira (2015), há um racismo tido como individual na situação relatada. É caracterizado como tal porque há um único sujeito (TEIXEIRA, 2015; ALMEIDA, 2018) que profere um discurso, que apesar de não ser diretamente um xingamento ou uma ofensa evidente, é direto (ALMEIDA, 2018) e é um discurso que deslegitima Stela como professora naquele espaço. Neste momento, estabelecem-se os lugares, que são distinguidos entre "nós" e "eles", que são os outros (VAN DIJK, 2012; MUNANGA, 1999), numa relação de poder; e são os outros que, por sua vez, "não podem ocupar um lugar que é nosso".

Ampliando o olhar para o mundo do trabalho e entendendo o setor da universidade como parte de uma organização maior, pode-se refletir também a respeito de um racismo tido como institucional, visto que pelas relações institucionais que se estabelecem - e pelo poder das instituições sob os sujeitos -, é neste espaço que as pessoas se formam e existem (ALMEIDA, 2018; SILVA, 2017). Assim como Almeida (2018) coloca, as instituições tem sua parcela diante dos comportamentos racistas, visto que em sua maioria é composta por grupos raciais hegemônicos que controlam as relações. No caso do universo universidade e docentes, como as pesquisas aqui citadas relatam (CARVALHO, 2006; TATE, 2013; GOMES, 2004), os negros são uma parcela bem pequena dos sujeitos como um todo.

O primeiro olhar da situação, caracterizado aqui por conta da primeira impressão como um racismo individual, é firmado por marcas racializadoras que carregam consigo tanto 
características físicas como também de caráter. São as posições e as características do negro que seguem aqui sendo compreendidas pelo "outro" como rótulos negativos, os quais tanto Stela como Cida lidam cotidianamente:

Sim, sim. O tempo todo. O tempo todo. Por exemplo na biblioteca, eu precisava pegar alguns livros mas esperei sair a carteirinha do SIAPE porque eu tinha certeza. Já pelas violências que eu já havia, né, vivido aqui e tal.... eu sabia que seria um documento fundamental. Assim que eu peguei esse número do SIAPE eu fui pra biblioteca pra pegar uns livros. Eu precisaria levar esses livros pra casa. E aí eu chego e me apresento. "Boa tarde, meu nome é Cida. Eu sou uma professora recém chegada aqui”, já desde fevereiro do ano passado, né. Eu tinha chegado aqui dia 31 de outubro. "Eu sou uma professora recém chegada aqui e tal. E eu gostaria de saber os trâmites legais pra fazer a carteirinha aqui da biblioteca porque eu preciso retirar alguns livros". E a atendente vira pro colega dela de trabalho e diz assim "Hã", rindo. "Ela está dizendo que é professora nova aqui" e me olha. E ele disse assim: "e qual a parte do que a professora disse você não entendeu?" Falei: ai, até que enfim alguém, né? E ela "não, nada". Só que quando ela volta pra digitar no teclado, a mão dela não chegou no teclado. Ela congelou. Uma mão segurando a carteirinha, que ela virava frente e verso. E a outra congelada, assim, em cima do teclado. E o outro colega percebendo a demora, ele se vira pra ela e fala assim: "algum problema?". "Não... não. não. Eu só estou olhando alguns detalhes". E continua e vira pra frente e pra trás a carteirinha e não ia com a mão. Ele se levantou do lugar dele, pediu licença a ela. Ela se levantou, ele sentou e falou: "olha, professora. Aqui estudantes e professores não têm diferença. Nós vamos cadastrar seu documento, é pelo seu CPF. A senhora vai digitar aqui. É assim pra todo mundo, tá". Eu falei: então tá. Fez o procedimento e ela continuava em pé com a minha carteirinha olhando frente e verso. Até que eu fui puxei a carteirinha desafiando com o olhar, né, de forma bruta. Ela se assustou, não falou nada e ficou acompanhando ele preencher os dados na plataforma. (Cida, Centro de Educação)

Quanto às expressões de racismo presentes neste segundo relato, reflexões estabelecidas na história de Stela podem ser trazidas para a vivência contada por Cida. Há, por exemplo, o racismo individual a partir do primeiro contato e logo em seguida da maneira como Cida é ignorada pela atendente. Tanto o relato de Stela quanto o de Cida sobre a reação dos funcionários trazem, também, outra reflexão: há um processo de racialização (IANNI, 2004) neste espaço hegemonicamente branco entre docentes. No caso do relato de Stela, é como se ao se questionar "como é que ela pode entrar aqui assim?" e estabelecer lugares, o funcionário estabelecesse também os não-lugares. "Porque têm regras", aquele espaço não era um espaço que Stela poderia adentrar, o que podemos enxergar como normas estabelecidas.

Institucionalmente, o racismo se faz presente (ALMEIDA, 2018; TEIXEIRA, 2015), quando o mundo do trabalho e o espaço da universidade normatizam e normalizam ações e processos que contribuem para um espaço racialmente hegemônico. São frases, questionamentos e ações discriminatórias de indivíduos que estruturam todo um espaço e uma relação de poder dentro do mesmo. Mesmo assim, novamente a presença de negros em espaços majoritariamente branco se comprova como uma forma de resistência. 
A partir disso, se voltarmos nossos olhares para como as relações raciais se deram no Brasil, podemos enxergar o negro da senzala que, dessa mesma maneira, tinha o seu lugar bem demarcado nas relações assim como o seu não lugar também. A escravidão molda o negro como raça inferior e, consequentemente a sociedade os distingue e as desigualdades são

produzidas e reproduzidas (MUNAGA, 2010; SCHWARCKZ, 2012; TEIXEIRA, 2015). Nesse sentido, é possível dimensionar um terceiro olhar para o racismo observado nas duas vivências, tido aqui como algo estrutural, uma vez que o racismo acaba sendo fruto de uma estrutural social conflituosa através da qual as relações como um todo foram se estabelecendo nos diferentes contextos da história (ALMEIDA, 2018). No caso dos negros, as posições são demarcadas e desiguais; os espaços ainda são, em sua maioria, de subalternidade.

\section{CONCLUSÕES}

Com base nas discussões apresentadas diante da história das relações raciais no Brasil, das diferentes expressões de racismo existente e do contexto universitário enquanto mundo do trabalho pautado em relações racializadoras, a importância do presente artigo está no fato de que há a necessidade de, nos estudos organizacionais, não somente identificar a presença de negros e negros em diferentes espaços de trabalho como também entender as experiências de vida e conflitos desses sujeitos. Dessa forma, com base no objetivo aqui apresentado, de compreender "como acontece o racismo e suas diferentes expressões no contexto universitário, considerando a vivência de docentes negros neste espaço”, quatro categorias de análise são criadas neste artigo: (1) "Na academia, ela nunca é considerada intelectual": mulher, docente e negra; (2) "Nós conseguimos ressignificar a estética negra": características físicas racializadoras; (3) "É como se eu ficasse um pouco menos preto": racismos e miscigenações e (4) “Como é que ela pode entrar aqui, assim? Da onde que vem?": a universidade como um "não lugar" para o negro.

No que diz respeito às diferentes expressões do racismo e como elas acontecem, as análises mostram que o racismo estrutural é visualizado em todas as categorias, corroborando com o que Almeida (2018) e Teixeira (2015) discutem: um mesmo comportamento racista pode ter faces que se complementam entre aquilo que é individual, institucional e estrutural. Com relação ao racismo individual, percebeu-se que há sempre uma abordagem direta entre quem pratica o ato e quem o recebe; um discurso, na maioria das vezes deslegitimador. No caso do racismo institucional, além de também deslegitimar, as expressões estabelecem 
normas que, consequentemente, delimitam um lugar no espaço da universidade enquanto instituição entre docentes negros e seus demais colegas. Ao perceber a expressão do racismo como estrutural e presente em todos os relatos e perpassando todas as demais possiblidades, aspectos como a mestiçagem, cor e ausência de capacidade intelectual são observados. Tais aspectos, como a fundamentação teórica nos mostra, sempre estiveram presentes nas relações raciais; demarcando espaços, definindo profissões e estabelecendo estruturas de desigualdade racial.

Entende-se como delimitação deste trabalho o fato que o mesmo identificar e analisa apenas questões que dizem respeito ao racismo e suas diferentes formas de expressão. Os relatos trazem indícios de outros pontos para investigação juntamente com o analisado e que são aqui apresentados como possiblidade de estudos futuros. As impressões estabelecidas pelos "outros" com relação aos docentes negros no contexto da universidade, por exemplo, podem ser entendidas e analisadas enquanto conceitos de estereótipos e fenótipos diante de tais expressões. A interseccionalidade também é uma temática percebida ao se observar os relatos das mulheres negras docentes e entender que, juntamente com o racismo, outras violências relacionadas ao gênero também acontecem no espaço da universidade. Nesse sentido a universidade - enquanto organização e mundo do trabalho - abre espaço em suas relações para que determinadas categorias, além da raça, possam influenciar e se sobrepor a outras e (re)produzir diferentes expressões racistas.

\section{REFERÊNCIAS}

ALMEIDA, S. L. O que é racismo estrutural? Belo Horizonte (MG): Letramento, 2018.

BACKES, J. L. Articulando raça e classe: efeitos para a construção da identidade afrodescendente. Educ.Soc., Campinas, v. 27, n. 95, p. 429-43, maio./ago. 2006.

BARDIN, A. Análise de conteúdo. 3. ed. Lisboa: Edições 70, 2004.

BENTO, M. A. S. BRANQUEAMENTO E BRA BRASIL. Resolução no 510, de 07 de abril de 2016. Dispõe sobre as normas aplicáveis a pesquisas em Ciências Humanas e Sociais. Conselho Nacional de Saúde, Brasília, 07 de abril de 2016. Disponível em: http://conselho.saude.gov.br/resolucoes/2016/Reso510.pdf. Acesso em: NQUITUDE NO BRASIL In: Psicologia social do racismo - estudos sobre branquitude e branqueamento no Brasil / Iray Carone, Maria Aparecida Silva Bento (Organizadoras) Petrópolis, RJ: Vozes, 2002, p. (25-58)

BRASIL. Resolução $n^{\circ}$ 510, de 07 de abril de 2016. Dispõe sobre as normas aplicáveis a pesquisas em Ciências Humanas e Sociais. Conselho Nacional de Saúde, Brasília, 07 de abril 
de 2016. Disponível em: http://conselho.saude.gov.br/resolucoes/2016/Reso510.pdf. Acesso em:10 de dezembro de 2019.

CARVALHO, J. J. O confinamento racial do mundo acadêmico brasileiro. REVISTA USP, São Paulo, n.68, p. 88-103, dezembro/fevereiro 2005-2006

CICONELLO. Alexandre. O desafio de eliminar o racismo no Brasil: a nova institucionalidade no combate à desigualdade racial. From Poverty to Power: Oxfam International, 2008

CLEALAND, D. P. When ideology clashes with reality: racial discrimination and black identity in contemporary Cuba. Ethnic and Racial Studies, 36:10, 1619-1636, 2013. DOI: $10.1080 / 01419870.2013 .783928$

COLBARI, A. A Análise de conteúdo e pesquisa empírica qualitativa. In: SOUZA, E. M. (Org.) Metodologias e analíticas qualitativas em pesquisa organizacional: uma abordagem teórico-conceitual. Vitória : EDUFES, 2014. 296 p. : il.

CONCEIÇÃO, E. B. DA. Mulher negra em terra de homem branco: mecanismos de reprodução de desigualdades. In: CARRIERI, A. DE P.; TEIXEIRA, J. C.; NASCIMENTO, M. C. R. (Eds.). . Gênero e trabalho: perspectivas, possibilidades e desafios no campo dos estudos organizacionais. Salvador: EDUFBA, 2016. p. 277-319.

CRESWELL, J. W. Projeto de Pesquisa: métodos qualitativos, quantitativos e mistos. Porto Alegre: Artmed, 2003.

FERNANDES, F. O negro no mundo dos brancos. 2. ed. rev. São Paulo: Global, 2007.

FERREIRA, R. F.; CAMARGO, A. C. As relações cotidianas e a construção da identidade negra. Psicol. cienc. prof., vol. 31, no. 2, Brasília, 2011.

GASKELL, G. Entrevistas individuais e em grupo. In: BAUER, M. W.; GASKELL, G. (Orgs.) Pesquisa qualitativa com texto, imagem e som: um manual prático. Petrópolis: Vozes, 2000.

GOMES, V. M. S. Indivíduos "FORA DE LUGAR": o caso dos(as) docentes negr(as) nas relações de trabalho na Universidade de Brasília. Sociedade e Estado, Brasília, v. 19, n. 1, p. 247-278, jan./jun. 2004

GUIMARÃES, A. S. F. Depois da Democracia Racial. Tempo Social, revista de sociologia da USP, v. 18 , n. 2, p. 269-287, nov./2006.

HALL, S. “Who needs 'identity'?”. In Du Gay, P., Evans, J. \& Redman, P. (Eds.). Identity: a reader (pp. 15-30). London: Sage Publications, 2000.

HOLANDA, M. A. P. G. Tornar-se negro: trajetórias de vida de professores universitários no Ceará. Tese (Doutorado) - Universidade Federal do Ceará. Faculdade de Educação. Programa de Pós-Graduação em Educação, Fortaleza (CE), 2009.

IANNI, O. Dialética das relações raciais. Estudos Avançados, 18 (50), 2004

LAGE, M. L. C.; SOUZA, E. M. . DA CABEÇA AOS PÉS: RACISMO E SEXISMO NO AMBIENTE ORGANIZACIONAL. RGSA (ANPAD), p. 55, 2017

LOPES, L. C. LÓPEZ, L.C. The concept of institutional racism: applications within the healthcare field. Interface - Comunic., Saude, Educ., v.16, n.40, p.121-34, jan./mar. 2012 
MIRANDA, A R A; CAPPELlE, M. C. A ; CUNHA, G. X. ; BUJATO, I. A. ; SIQUEIRA, R. B. ; SAMPAIO, J. M. . 'Isso já Está Superado!' A Justificação do Preconceito em Organizações Bancárias Que Possuem Programas de Gestão da Diversidade. In: Encontro da Associação Nacional de Pós-graduação em Administração, 2015, Belo Horizonte. Anais do XXXIX EnANPAD, 2015

MUNANGA, K. Redescutindo a mestiçagem no Brasil: identidade nacional versus identidade negra / Kabengele Munanga. - Petrópolis, RJ : Vozes, 1999.

MUNANGA, K. Algumas considerações sobre "raça", ação afirmativa e identidade negra no Brasil: fundamentos antropológicos. Revista USP, São Paulo, n.68, p. 46-57, dezembro/fevereiro 2005-2006.

Teoria social e relações raciais no Brasil contemporâneo. Cadernos

Penesb-Periódico do Programa de Educação sobre o Negro na Sociedade Brasileira (Especial curso ERER), n. 12, p. 1-384, 2010

NADAL, K. L.; ESCOBAR, K. M. V.; PRADO, G. T.; DAVID, E. J. R.; HAYNES, K. Racial Microaggressions and the Filipino American Experience: Recommendations for Counseling and Development. Journal of Multicultural counseling and development, july 2012, Vol. 40

NASCIMENTO, W. S. A importância da teoria das representações sociais para os estudos étnicos no Brasil: balanço teórico-conceitual. DIÁLOGOS \& CIÊNCIA - REVISTA DA REDE DE ENSINO FTC. Ano II, n. 8, março 2009.

NASCIMENTO, M. C. R.; OLIVEIRA, J. S.; TEIXEIRA, J. C.; CARRIERI, A. P. Com que cor eu vou pro shopping de BH que você me convidou? In: ENCONTRO ANUAL DA 16 ASSOCIAÇÃO NACIONAL DE PÓSGRADUAÇÃO E PESQUISA EM ADMINISTRAÇÃO, XXXVII, 2003, Rio de Janeiro. Anais ... Rio de Janeiro: ANPAD, 2013.

NOGUEIRA, O. Preconceito racial de marca e preconceito racial de origem: sugestão de um quadro de referência para a interpretação do material sobre relações raciais no Brasil. Tempo Social, v. 19, n. 1, p. 287-308, 2007.

OLVEIRA, J. S. Subjetividade e Raça na (Des)Construção Simbólica da Pesquisadora em Campo: Uma Etnografia Multissituada em Diferentes Contextos Culturais. In: ENCONTRO ANUAL DA 16 ASSOCIAÇÃO NACIONAL DE PÓS-GRADUAÇÃO E PESQUISA EM ADMINISTRAÇÃO, XXXIX, 2015, Belo Horizonte. Anais ... Belo Horizonte: ANPAD, 2015.

PEREIRA, J. B. B. Diversidade e pluralidade: o negro na sociedade brasileira. Revista USP, São Paulo, n.89, p. 278-284, março/maio 2011

RÖESCH, I. C. Docentes negros: Imaginários, Territórios, Fronteiras no Ensino Universitário. Universidade Federal de Santa Maria, Centro de Educação. Santa Maria, 2014.

SANSONE, L. Nem somente preto ou negro: o sistema de classificação racial no Brasil que muda. Afro-Ásia, 18 (1996), 165-187.

SILVA, E. L.; SILVA, J. A. Contribuições gramscianas sobre raça, identidade cultural e velhice na perspectiva de Stuart Hall. R. Katál., Florianópolis, v. 20, n. 1, p. 95-102, jan./abr. 2017 
SILVA, M. A. B. Racismo institucional: pontos para reflexão. Laplage em Revista (Sorocaba), vol. 3, n. 1, jan-abr. 2017, p. 127-136.

SOUZA, E. M. PROCESSOS DE RACIALIZAÇÃO: Inteligibilidade, Hibridade e Identidade Racial em Evidência. E\&G Economia e Gestão, Belo Horizonte, v. 17, n. 48, Set./Dez. 2017.

SCHWARCZ, L. M.. Nem preto nem branco, muito pelo contrário: cor e raça na sociabilidade brasileira. - $1^{\text {a }}$ - ed. — São Paulo : Claro Enigma, 2012

TATE, S. A. Racial affective economies, disalienation and 'race made ordinary'. Ethnic and Racial Studies, Vol. 37, No. 13, 2475-2490, 2014.

TEIXEIRA, J. C. As artes e práticas cotidianas de viver, cuidas, resistir e fazer das empregadas domésticas. Universidade Federal de Minas Gerais. Centro de Pós Graduação e Pesquisas em Administração, 2015.

TEIXEIRA, J. C. Pós-Estruturalismo sem caricaturas. Encontro de Estudos Organizacionais da ANPAD. Anais...Rio de Janeiro: ANPAD, 2012.

VAN DIJK, T.A. Discurso e poder / Teun A. van Dijk; Judith Hoffnagel, Karina Falcone, organização. 2. ed., $1^{\text {a }}$ reimpressão - São Paulo; Contexto, 2012.

WERNECK, J. Racismo institucional e saúde da população negra. Saúde Soc. São Paulo, v. 25, n.3, p.535-549, 2016 